\title{
CONTRIBUIÇÕES DA EDUCAÇÃO AMBIENTAL PARA MUDANÇAS SOCIOAMBIENTAIS QUE CONTRIBUAM NO ENFRENTAMENTO DA PANDEMIA
}

\author{
Adriana Maria Imperador ${ }^{1}$ \\ Luciana Botezelli² \\ Daniela Rocha Teixeira Riondet-Costa ${ }^{3}$
}

Resumo: O mundo vive um momento ímpar nas relações humanas quando comparado às últimas décadas. Sistemas econômicos e sociais estão sendo colocados à prova diante da nova realidade. O objetivo deste trabalho é refletir, tendo como pano de fundo a pandemia, acerca das mudanças comportamentais da sociedade e tratar de alguns reflexos socioeconômicos e ambientais nos pequenos arranjos econômicos locais. Percebe-se que há diversas mudanças positivas, mesmo tendo como motivador algo negativo como a pandemia, mas continuam persistindo comportamentos negativos. Espera-se que as novas construções benéficas sejam mantidas na sociedade pós-pandemia e um dos instrumentos para tal é a Educação Ambiental.

Palavras-chave: Comércio local; Mudanças de atitude; Transformações sociais; Educação Ambiental; Relação homem ambiente.

\footnotetext{
1 Universidade Federal de Alfenas, campus Poços de Caldas, MG. E-mail: adriana.imperador@unifalmg.edu.br, http://lattes.cnpq.br/6511962778909776

2 Universidade Federal de Alfenas, campus Poços de Caldas, MG. E-mail: luciana.botezelli@gmail.com, http://lattes.cnpq.br/9663804820756262

3 Universidade Federal de Itajubá. E-mail: danielart@unifei.edu.br. http://lattes.cnpq.br/6248878709762228
} 
Abstract: The world is experiencing a unique moment in human relations, when compared to the last decades. Economic and social systems are being put to the test in the face of the new reality. The aim of this paper is to reflect, against the background of the pandemic, about the behavioral changes in society and to address some socioeconomic and environmental impacts in small local economic arrangements. It can be seen that there are several positive changes, even if something negative is motivated, such as the pandemic, but negative behaviors persist. New beneficial constructions are expected to be maintained in the postpandemic society and one of the instruments for this is environmental education.

Keywords: Local commerce; Attitude changes; Social transformations; Environmental education; Relationship man environment.

\section{Introdução}

No início de março de 2020, a Organização Mundial da Saúde (OMS) declarou que estávamos em pandemia do novo coronavírus. Deste então, estamos vivendo um período de transformação drástica de comportamento humano, provavelmente jamais experimentada. A revolução tecnológica é um dos fatores que influencia diretamente estas transformações, tornando a sociedade mais conectada e informada a respeito das ações de combate à pandemia e criando oportunidades de mudança de paradigma em relação à muitos conceitos estruturados e estagnados de comércio, geração de renda e relações socioambientais.

De acordo com Silva (2020, p.5), os reflexos diretos e imediatos na economia real de um país são empresas encerrando as atividades, matériaprima que não atende à demanda local, paralisando a produção e aumentando do desemprego. O Banco Nacional de Desenvolvimento Econômico e Social (BNDES) lançou, tardiamente, as primeiras medidas para reforçar o caixa de empresas e apoiar trabalhadores que enfrentam os efeitos do coronavírus. As medidas ajudarão as empresas a enfrentar dificuldades de caixa e manter mais alguns empregos, mas não serão suficientes por conta das políticas de isolamento social implementadas sob recomendação do Ministério da Saúde (MS) e da Organização Mundial da Saúde pelos estados e municípios a contragosto dos discursos do presidente ou mesmo do ministro da economia.

Visando reduzir os impactos nas empresas e manter parte dos empregos formais, o governo tem lançado alguns pacotes econômicos, que, segundo Maranhão (2020, p.36), não serão suficientes para manter a economia aquecida devido ao isolamento social e um possível lockdown econômico. Vale lembrar que estas medidas econômicas de "auxílio" às empresas são empréstimos que serão cobrados futuramente fato que aumenta, ainda mais, a pressão sobre os pequenos e médios empresários gerando mais problemas sociais e econômicos.

No contexto brasileiro da economia de base comunitária, o grande 
impactos econômicos locais desencadeados pelo isolamento. De acordo com a Nota Técnica oㅜ 32 do Instituto de Pesquisa Aplicada - IPEA, do Ministério da Economia, intitulada "Estratégias de coordenação governamental na crise da COVID-19" que traz uma inflexão para a trajetória nacional de desenvolvimento, subsídios e propostas, é evidente que a proteção social como forma de reduzir os impactos sobre parcelas de maior vulnerabilidade social e econômica se faz necessária (SCHMIDT et al., 2020, p.13.).

Nesse sentido, se tornou necessária a atuação direta do governo, como a implementação da Lei no 13.982 de 2 de abril de 2020 (BRASIL, 2020), que estabelece ações de proteção social em meio à situação emergencial de socorro aos mais vulneráveis. Todavia, para muitas famílias que tiveram sua fonte de renda comprometida pelo isolamento social, essa ajuda emergencial foi importante, mas não suficiente.

Visando a complementação da renda nesse novo cenário, muitas cidades criaram redes de solidariedade e estímulo ao comércio local de pequenos produtores, estruturando o comércio e transporte direto do produtor ao consumidor, e estruturando circuitos de divulgação e colaboração.

Considerando os 17 Objetivos de Desenvolvimento Sustentável da Organização das Nações Unidas, que reconhece que a erradicação da pobreza em todas as suas formas e dimensões é o maior desafio global e um requisito indispensável para o desenvolvimento sustentável (ONU, 2015, p.1), destacamos neste artigo reflexivo o item 11 "Tornar as cidades e os assentamentos humanos inclusivos, seguros, resilientes e sustentáveis" para apoiar nossa visão crítica sobre o enfrentamento do coronavírus em pequenos arranjos econômicos locais no Brasil.

O objetivo deste artigo é trazer reflexões a respeito das mudanças comportamentais e relacionadas às questões socioeconômicas e ambientais na sociedade, evidenciadas pela pandemia de COVID-19.

\section{Uma nova forma de viver e pensar?}

Sem dúvida a epidemia do novo coronavírus trouxe à humanidade uma maneira diferente de pensar, e quem sabe repensar, seu dia a dia.

A vida deixou de ser marcada pela rotina dos horários e funções. $O$ tempo deixou de ser tanto chronos e passou a ser muito mais kairós, querendo nós ou não. Isto acarretou à humanidade doses variáveis de desespero e aflição, tanto pela eminência de uma doença desconhecida quanto pelo pouco autoconhecimento. Fato é que a vida mudou seu curso e os que viviam anestesiados em suas rotinas tiveram que permear outra realidade.

Muitos hoje não conhecem/reconhecem a si próprios e foram forçados a estar consigo mesmo, restritos num espaço. Ou ainda, estar com os seus doces, estranhos ou, em alguns casos, perversos familiares. Mesmo antes da

pandemia de COVID-19 a violência sexual ou física atingia 243 milhões de 
mulheres e meninas de 15 a 49 anos, praticada por parceiro íntimo (ONU, 2020). Segundo o Observatório da Mulher contra a Violência OMV (2020), a violência contra a mulher cresceu consideravelmente durante 0 isolamento, na maior parte das ocorrências, $41 \%$ dos casos, a agressão foi cometida por marido, companheiro ou namorado. O isolamento social constitui uma medida importante recomendada pela Organização Mundial da Saúde (OMS) (OMS, 2020) para diminuir a taxa de contaminação pelo novo coronavírus, porém traz consigo o dilema da permanência junto ao agressor e a maior dificuldade para pedidos de ajuda.

Talvez, como colocado por Ferreira Junior e Santa Rita (2020, p.466), essa crise traga como principal contribuição a relevância da ciência para que se caminhe efetivamente no controle de pandemias.

Parece ter chegado o momento de verdadeiramente se pensar sobre sustentabilidade e seus pilares. Neste momento estes são essenciais para que a vida continue com qualidade, já que a somatória de tantos problemas ambientais parece culminar em desordens de grande vulto, como a emergência de doenças.

\section{Comércio local e oportunidades}

Considerando que estamos no início de junho de 2020, uma mudança notável foi em relação ao comércio. Com a restrição de circulação e apenas comércio essencial aberto, devido aos decretos sancionados em meados de março, a busca pelos comércios locais ou entrega personalizada cresceram grandemente, assim como as alternativas de retirada no local ou entregas em casa.

Mesmo com a chegada da flexibilização do comércio em diversas cidades, em maio de 2020, muitos consumidores mantiveram o hábito de receber em casa suas compras. Segundo Serviço Brasileiro de Apoio às Micro e Pequenas Empresas - Sebrae (s/d), a mobilização da sociedade em prol do favorecimento do comércio local é a melhor alternativa para manutenção das micro e pequenas empresas nestes tempos de pandemia.

Apesar das flexibilizações relacionadas ao comércio de produtos e serviços, sabemos que a pandemia é algo que se estenderá por algum tempo, até que venha uma vacina, então pensar as alternativas torna-se algo fundamental para garantia da saúde financeira de muitas famílias dependentes diretamente do comércio. Favorecer o pequeno estabelecimento é dar oportunidade de manutenção financeira a estes, já que, como reitera Sebrae (s/d), estão sendo muito mais impactados que médios e grandes empresários.

Os arranjos locais facilitam a circulação financeira na comunidade, partilhando direta ou indiretamente seus bônus. A menor distância física, muitas vezes, pode facilitar o contato e "propaganda" entre produtores, além das relações socioafetivas que podem ser construídas. 
Alguns setores particularmente tiveram suas atividades alavancadas, como a limpeza especializada de veículos, clínicas, hospitais e empresas; as áreas de tecnologia da informação, inclusive com a migração de comerciantes que antes da pandemia só atuavam presencialmente; motoristas de transporte de carga; empresas de distribuição dentro dos municípios, incluindo os motociclistas que fazem entregas (motoboys).

\section{As mudanças positivas notadas pela restrição da circulação humana}

Neste favorecimento do comércio local, muitas vezes, está envolvida a menor movimentação de pessoas e de veículos. Esta última favoreceu notadamente a diminuição dos ruídos e emissões de gases poluentes derivados dos motores movidos a combustíveis fósseis. Na China foram registradas reduções nas emissões de poluentes da ordem de $25 \%$ em três semanas, que correspondem a uma diminuição de $6 \%$ da emissão global, segundo cálculos de Lauri Myllyvirta do Centro de Pesquisa em Energia e Ar Limpo dos Estados Unidos da América (BBC, 2020).

Estas medidas realizadas em diversas partes do planeta repetem-se em diferentes escalas e, considerando o conhecimento relativo aos efeitos da poluição sobre o homem e o ambiente, acredita-se que a qualidade ambiental tenha melhorado expressivamente. Esta alteração benéfica ao ambiente, trazida por algo bastante ruim - a pandemia -, deverá ser passageira. Contudo, seus efeitos podem trazer reflexões importantes sobre o impacto humano sobre o meio ambiente e a importância de se tomar medidas, assim como a necessidade de elaboração de políticas públicas, voltadas à minimização destes impactos.

As incursões da fauna no ambiente urbano também foram notadas, fotografadas e divulgadas em diversos países. Da Silva e Coelho (2020) reproduziram algumas fotos de diferentes autores em seu estudo, apresentando fotos de cervos em estação do metrô, no Japão; cisnes nos canais de Veneza e o clareamento das águas destes mesmos canais permitindo a visualização dos peixes; javalis em área urbana na Sardenha, Itália; onça parda caminhando pelas ruas no Chile; lobo-guará na área urbana em Volta Redonda, RJ.

\section{Sugestões de contribuição da Educação Ambiental no processo}

Os impactos negativos da ação do homem no meio ambiente resultam em alterações significativas nas relações ecológicas, como exemplo a migração de diversas espécies de animais silvestres de seu habitat natural para áreas urbanizadas. Essa proximidade aumenta o risco de contato de espécies silvestres e espécies domesticadas, aumentando as possibilidades de doenças causadas por zoonoses virais (ASANO,2015, p.57).

Almeida e colaboradores (2019, p. 45), no estudo intitulado "Multifatorialidade em saúde ambiental", concluem que para evitar a 
degradação ambiental, a ciência deve estreitar o laço com a comunidade, por meio de metodologias simplificadas, tecnologias adaptadas e práticas participativas. Os autores apontam ainda que, a inclusão de aspectos ambientais para tomada de decisão a respeito de políticas públicas em saúde deve envolver a sociedade civil organizada e a comunidade científica.

Em uma visão contemporânea da Educação Ambiental, considerando o ecologismo dos pobres, também conhecido como justiça ambiental (MARTÍNEZ ALIER, 2007), considera que alguns grupos sociais sejam privados do acesso aos recursos e serviços ambientais, considerando a desigualdade social devido à acumulação capitalista.

Segundo Loureiro e colaboradores (2009, p.83), a existência de grande desigualdade social e injustiça no Brasil tem afetado as populações marginalizadas e instaladas em instalações periféricas, sendo estes protagonistas de movimentos que reivindicam a justiça ambiental e a mudança no atual modelo econômico.

De acordo com o documento intitulado "Os 17 Objetivos de Desenvolvimento Sustentável" (ONU, 2015), todos os países interessados estão atuando em parceria colaborativa para desenvolver ações cruciais para a humanidade e o planeta até o ano de 2030. O documento ainda considera que estas ações objetivam reduzir a pobreza e a fome e garantir a dignidade e igualdade em um ambiente saudável e ainda proteger o planeta por meio da redução da degradação, do incentivo ao meio de consumo e produção sustentáveis, da gestão dos recursos naturais, visando que os recursos estejam disponíveis para as presentes e futuras gerações.

A agenda ainda propõe a Parceria Global para o Desenvolvimento Sustentável, objetivando o espírito de solidariedade mundial para suprir as necessidades dos mais vulneráveis.

O objetivo 11, especificamente, prevê garantir até 2030 o acesso de todos à residências que atendam condições de segurança, acesso a serviços básicos, valores acessíveis, além de apoiar a economia que favoreça relações sociais benéficas entre áreas urbanas, periurbanas e rurais, reforçando 0 planejamento nacional e regional de desenvolvimento.

Em um momento de crise gerado pela pandemia de coronavírus, percebemos diversas iniciativas que corroboram com o protagonismo das populações mais vulneráveis, sendo criadas verdadeiras redes de colaboração para o enfrentamento de anormalidade. Enquanto aguardam por programas governamentais, que por vezes não atingem muitas famílias ou não se mostram suficientes, comunidades se unem em redes de solidariedade que atendem de forma emergencial os mais vulneráveis por meio de obtenção e destinação de doações e de rearranjos econômicos locais, muitas vezes negligenciados em outros momentos.

Podemos citar diversas ações desenvolvidas pelas comunidades locais espalhadas pelo país durante o período de isolamento social desencadeado pela pandemia do novo coronavírus. Dentre as ações, o incentivo ao comércio 
local foi extremamente valorizado por diversas comunidades. Por meio de mídias sociais e programa de rádio e televisão regionais, houve a promoção do consumo de pequenos comércios locais e das produções de alimentos e produtos artesanais. Essa ação contribuiu para a geração de renda de pequenos produtores e, do ponto de vista ambiental, favoreceu a redução da emissão de poluentes atmosféricos devido ao menor deslocamento de frete para a entrega, bem como valorizou produções de alimentos orgânicos.

Outra ação relevante foi a promoção de troca de bens na substituição do comércio fechado e a redução da renda dos trabalhadores informais. Considerando que muitas famílias aproveitaram o momento de isolamento para reorganizar os armários e guarda-roupas, houve uma disponibilidade de produtos como roupas e objetos destinados para troca. Foram observadas ações de bazares de troca de roupas arrecadadas por alimento, sendo estes destinados à comunidade carente.

A redução do consumo também foi efetiva, uma vez que houve a redução de renda afetou diversas famílias e o fechamento do comércio para produtos não essenciais. A prioridade por alimentos e medicamentos, em comparação aos bens como roupas, calcados e produtos estéticos, produziram uma onda de redução ao consumo.

Outra campanha divulgada nas mídias foi a de evitar o estoque de produtos para garantir o abastecimento das famílias. É fato que em momentos de crise muitas famílias decidem por estocar produtos temendo 0 desabastecimento. $O$ estoque de produtos pode gerar, a princípio, o consumo excessivo de produtos e, muitas vezes, a inutilização de produtos que extrapolaram o prazo de validade.

Finalizando a lista de ações, podemos ainda citar a rede de solidariedade de doação de produtos alimentares, medicamento e de higiene pessoal realizada por diversos segmentos de empresários locais e líderes comunitários.

De acordo com o Programa das Nações Unidas para o Desenvolvimento (PNUD, 2016, p. 12), os países devem mobilizar parcerias necessárias para implementar a Agenda por meio de uma Parceria Global para - Desenvolvimento Sustentável, pautada na solidariedade fortalecida, favorecendo os mais pobres e vulneráveis, com a participação efetiva de toda sociedade.

A prática da Educação Ambiental, no contexto da justiça ambiental, se torna uma proposta indispensável para promover e fortalecer as redes de solidariedades locais e criar mecanismos de comunicação para a promoção de desenvolvimento sustentável.

O protagonismo da comunidade nos arranjos locais, para 0 fortalecimento e sobrevivência dos mais vulneráveis no momento de pandemia, deve servir de modelo de construção para uma sociedade mais justa e consciente em relação à disposição e acesso aos recursos naturais. 


\section{Conclusões}

O isolamento social trouxe arranjos emergenciais que despertaram a cooperação e solidariedade, representada pelas diversas ações organizadas e desenvolvidas pela própria comunidade. Essas ações foram essenciais para a redução dos impactos da pandemia em diversas comunidades vulneráveis do país.

O retorno ao cotidiano de trabalho e estudo presencial pós isolamento social trará diversos desafios como o incremento do crescimento econômico, a redução da desigualdade social, a geração de emprego e renda e a proposta de uma educação mais inclusiva em todos os aspectos.

Considerando as experiências vivenciadas pela sociedade, espera-se que as políticas públicas favoreçam comunidades que vivem às margens da sociedade, considerando aspectos de saúde, educação e renda.

O grande desafio da Educação Ambiental no momento pós-pandemia é colaborar com essa nova realidade e contribuir com a construção de uma sociedade mais justa e solidária, valorizando os recursos naturais, a ciência e a conservação da natureza.

\section{Referências Bibliográficas}

ALMEIDA, J.R.; SILVA, C.E.; SILVA, C.V.V.; AGUIAR, L.A.; GARCIA, V.S.; SOUZA, C. P.; LENS, E. R. S.; LINS, G. A.; ALMEIDA, S. M. Multifatorialidade em saúde ambiental. Environmental Scientiae: Jun, Jul, Ago, Set, Out, Nov 2019: Edição Especial Gestão e Vigilância em Saúde Ambiental: p. 26-47. Janeiro/2020.

ASANO, K.M. Ocorrência e caracterização molecular de coronavírus e rotavírus do grupo A em quirópteros do Estado de São Paulo. 2014. Tese (Doutorado em Epidemiologia Experimental Aplicada às Zoonoses) - Faculdade de Medicina Veterinária e Zootecnia, University of São Paulo, São Paulo, 2015. doi:10.11606/T.10.2016.tde-18082015-113847. Acesso em: 2020-04-21.

BBC. Como epidemia de coronavírus pode ter efeito positivo no meio ambiente. 02 de março de 2020. Disponível em: $<$ https://www.bbc.com/portuguese/internacional-51682790> . Acesso em maio 2020.

BRASIL. Lei no 13.982, de 2 de abril 2020. Disponível em: $<$ http://www.planalto.gov.br/ccivil 03/ ato2019-2022/2020/lei/L13982.htm> Acesso em abril de 2020.

DA SILVA, E.R.; COELHO, L.B.N. Sobre incursões da fauna silvestre a áreas urbanas durante a pandemia do novo coronavírus. Revista A Bruxa, v. 4, n. 2, p. 1-13, março de 2020 . 
FERREIRA JUNIOR, R.R.; SANTA RITA, L.P. Impactos da COVID-19 na economia: limites, desafios e políticas. Cadernos de Prospecção, v.13, n.2, Edição Especial, p.459-476, 2020.

LOUREIRO, C.F.B.; BARBOSA, G.L.; ZBOROMSKI, M.B. Os vários "ecologismos dos pobres" e as relações de dominação no campo ambiental. In: LOUREIRO, C.F.B., LAYRARGUES, P.P, CASTRO, R. S.(orgs) Repensar a Educação Ambiental: um olhar crítico. - São Paulo: Cortez, 2009.

MARANHÃO, R.A.; SENHORAS, E.M. Pacote Econômico Governamental e o papel do BNDES na Guerra contra o novo coronavírus. Boletim de Conjuntura (BOCA), [S.I.], v. 2, n. 4, p. 27-39, apr. 2020.

MARTíNEZ ALIER, J. O Ecologismo dos Pobres: conflitos ambientais e linguagens de valoração. São Paulo: Contexto, 2007.

OMV. Observatório da Mulher contra a Violência. Violência doméstica em tempos de COVID-19. Boletim Mulheres e seus Temas Emergentes, abril 2020.

Disponível

em:

$<$ https://www12.senado.leg.br/institucional/omv/pdfs/violencia-domestica-em-

tempos-de-COVID-19> . Acesso em maio de 2020.

ONU. Organização das Nações Unidas. Violência contra mulheres e meninas é pandemia das sombras. 08 de abril de 2020. Disponível em: $<$ https://nacoesunidas.org/artigo-violencia-contra-mulheres-e-meninas-epandemia-das-sombras/amp > . Acesso em abril de 2020.

ONU. Organização das Nações Unidas. Transformando nosso mundo: a agenda 2030 para o desenvolvimento sustentável. Brasília: 2015, 41p.

SEBRAE. Serviço Brasileiro de Apoio às Micro e Pequenas Empresas. Comprar do comércio local durante crise é bom para todos. s/d. Disponível em: $\quad<$ https://m.sebrae.com.br/sites/PortalSebrae/ufs/pb/artigos/comprar-docomercio-local-durante-crise-e-bom-para-

todos,fedfOfd17ef41710VgnVCM1000004c00210aRCRD>. Acesso em maio 2020.

SILVA, O.T. O salto ainda mais mortal que o da mercadoria e a pandemia do coronavírus. Espaço e Economia [Online], | 2020. Disponível em: $<$ http://journals.openedition.org/espacoeconomia/10822>. Acesso em abril de 2020.

SCHMIDT, F.; MELLO, J.; CAVALCANTE, P. Estratégias de coordenação governamental na crise da COVID-19. Nota Técnica $\mathrm{n}^{\circ} 32$ da Diretoria de Estudos e Políticas do Estado, das Instituições e da Democracia, p.24. 2020.

PNUD, Programa das Nações Unidas para o Desenvolvimento. As perguntas mais frequentes sobre os Objetivos de Desenvolvimento Sustentável (ODS), 29 jun. $2016 . \quad$ Disponível em: <http://www.br.undp.org/content/brazil/pt/home/post-2015/materiais/perguntase-respostas.html>. Acesso em: 18 abr. 2020. 